\title{
Expression of a hyperactive androgen receptor leads to androgen-independent growth of prostate cancer cells
}

\author{
Chen-Lin Hsieh, Changmeng Cai ${ }^{\dagger}{ }^{\dagger}$, Ahmed Giwa, Aaronica Bivins, Shao-Yong Chen ${ }^{\dagger}$, \\ Dina Sabry, Kumara Govardhan and Lirim Shemshedini
}

Department of Biological Sciences, University of Toledo, Toledo, Ohio 43606, USA

(Correspondence should be addressed to L Shemshedini; Email: Ishemsh@utnet.utoledo.edu)

${ }^{*} \mathrm{C}-\mathrm{L}$ Hsieh and C Cai contributed equally to this work

${ }^{\dagger} \mathrm{C}$ Cai and S-Y Chen are now at Beth Israel Deaconess Medical Center, 330 Brookline Avenue, Boston, Massachusetts, USA

\begin{abstract}
Cellular changes that affect the androgen receptor (AR) can cause prostate cancer to transition from androgen dependent to androgen independent, which is usually lethal. One common change in prostate tumors is overexpression of the AR, which has been shown to lead to androgen-independent growth of prostate cancer cells. This led us to hypothesize that expression of a hyperactive AR would be sufficient for androgen-independent growth of prostate cancer cells. To test this hypothesis, stable lune cancer prostate (LNCaP) cell lines were generated, which express a virion phosphoprotein (VP)16-AR hybrid protein that contains full-length AR fused to the strong viral transcriptional activation domain VP16. This fusion protein elicited as much as a 20-fold stronger transcriptional activity than the natural AR. Stable expression of VP16-AR in LNCaP cells yielded androgen-independent cell proliferation, while under the same growth conditions the parental LNCaP cells exhibited only androgen-dependent growth. These results show that expression of a hyperactive AR is sufficient for androgen-independent growth of prostate cancer cells. To study the molecular basis of this enhanced growth, we measured the expression of soluble guanylyl cyclase- $\alpha 1$ (sGC $\alpha 1$ ), a subunit of the sGC, an androgen-regulated gene that has been shown to be involved in prostate cancer cell growth. Interestingly, the expression of $\mathrm{SGC} \alpha 1$ is androgen independent in VP16-AR-expressing cells, in contrast to its androgen-induced expression in control LNCaP cells. RNA 1 -dependent inhibition of $\mathrm{sGC} \alpha 1$ expression resulted in significantly reduced proliferation of VP16-AR cells, implicating an important role for SGC $\alpha 1$ in the androgen-independent growth of these cells.
\end{abstract}

Journal of Molecular Endocrinology (2008) 41, 13-23

\section{Introduction}

Prostate cancer is an epithelial-derived cancer (Cussenot et al. 1994) that involves the action of androgens and androgen receptor (AR), a ligand-dependent transcription factor (Chang et al. 1988). This liganded AR is essential for the growth and survival of primary tumors (androgen-dependent prostate cancer cells; reviewed by Jenster 1999). The primary treatment for prostate cancer is aimed at disrupting the androgen-AR interaction (Eder et al. 2000, Jiang et al. 2004). In the prostate, two main forms of androgens are secreted: testosterone and dihydrotestosterone (DHT). Although DHT is the more potent form, both forms are involved in the development of both the prostate and male secondary sex characteristics (Singh et al. 2000). The liganded AR forms a homodimer and binds to the androgenresponsive elements (AREs) found on the promoters of target genes to regulate gene expression (reviewed in Kastner et al. 1995, Mangelsdorf \& Evans 1995, Mangelsdorf et al. 1995, Thummel 1995, Beato \& Klug 2000).
The AR is important not only in the development of prostate cancer but also in its progression to the usually lethal androgen-independent form (reviewed in Jenster 1999). Several mechanisms for the transition of prostate cancer from a hormone-sensitive to hormone-refractory form have been proposed. First, the AR pathway is bypassed by activation of oncogenes and/or inactivation of tumor suppressor genes (Jenster 1999). In some cases, this can lead to the loss of AR expression by either gene deletion/mutation or DNA methylation, as exemplified by several prostate cancer cell lines (Russell \& Kingsley 2003). Another mechanism is ligand-independent activation of $\mathrm{AR}$, which can be mediated by several growth factors, including keratinocyte growth factor, epidermal growth factor, and interleukin-6 (Smith et al. 2001, Roznovanu et al. 2005). AR mutations that broaden ligand specificity are common in late-stage prostate cancer (Brinkmann et al. 1995, Marcelli et al. 2000), and recent evidence has shown that such mutations cannot only initiate prostate cancer but also cause it to progress to a hormonerefractory stage in transgenic mice (Han et al. 2005). 
Lastly, AR gene amplifications are observed in $28-30 \%$ of recurring tumors following anti-androgen therapy, leading to increased levels of AR and presumably to a more sensitized and active AR pathway (Jenster 1999). In support of this, it was recently demonstrated that AR overexpression is sufficient to convert androgen-dependent prostate cancer to an androgen-independent form (Chen et al. 2004).

Since these earlier studies demonstrate that hormoneindependent prostate cancer cells exhibit increased AR expression and, thus, transcriptional activity (Kokontis et al. 2005), and AR function has been linked to the development and progression of androgen-independent prostate cancer form, we sought to study the direct effect of AR transcriptional activity on the growth of prostate cancer cells. Hence, we hypothesized that expression of a hyperactive AR can convert the growth of prostate cancer cells from androgen dependent to androgen independent. Our data show that fusion of the activation function of virion phosphoprotein (VP) 16 (Tiley et al. 1992) to the $\mathrm{AR}$ renders a receptor that has significantly higher transcriptional activity than the native AR. Stable expression of VP16-AR in prostate cancer cells yielded androgen-independent cell proliferation. Importantly, this androgen-independent growth correlated with androgen-independent expression of soluble guanylyl cyclase$\alpha 1$ (sGC $\alpha 1$ ), an AR-regulated gene that has been previously implicated in hormone-refractory prostate cancer cell growth (Cai et al. 2007a). These data show that mechanisms that elevate AR transcriptional activity can lead to hormone-refractory growth of prostate cancer cells and suggest that androgen-independent expression of sGC $\alpha 1$, and perhaps other AR-regulated genes, may be responsible for the cell growth.

\section{Materials and methods}

\section{Plasmids}

To make VP16-AR/pCI-Neo, hAR/pSG5 (Bubulya et al. 1996) was digested with BamHI/DraI and inserted into pcDNA3.1/Zeo $(+)$, generating hAR/pcDNA3.1/ Zeo $(+)$. The VP16 transactivation domain (amino acids 414-490; Berger et al. 1990) was synthesized by PCR and inserted into the BamHI site of AR/pcDNA3.1/Zeo $(+)$, making VP16-hAR/pcDNA3.1/Zeo $(+)$. VP16-hAR was digested out of VP16-hAR/pcDNA3.1/Zeo $(+)$ with NheI and NotI and inserted using these same restriction sites into pCI-Neo, yielding VP16-AR/pCI-Neo.

The reporter plasmids MMTV-CAT, PSA-CAT, and hKLK2CAT have been described previously (Bubulya et al. 1996). Transfection efficiency was standardized according to $\beta$-galactosidase activity, which comes from the transfected pCH110 plasmid (Shenk et al. 2001). The PSA-Luc (Shenk et al. 2001) and ARE4-Luc
(Chen et al. 2006a) luciferase reporters have been described previously.

\section{Transient transfection and reporter gene assays}

Transient transfection with reporter gene plasmids of LNCaP and stable cell lines was carried out using the $\mathrm{CaPO}_{4}$ method as described previously (Chen et al. $2006 b$ ). For all transfection experiments, cells were transfected with $2 \mu \mathrm{g}$ pCH110 and enough pTL1 to bring the final plasmid amount to $10 \mu \mathrm{g}$ per dish (Chen et al. 2006b). Whole cell extracts were prepared and subjected to CAT (Bubulya et al. 2001) or luciferase assays (Cai et al. 2007a). CAT assay results were quantified using the Bio-Rad Molecular Imager FX and Quantify One software (Philadelphia, PA, USA).

\section{Generation and growth of stable cell lines}

Generation of stable LNCaP cell lines using a pCI-Neobased plasmid has been already described (Chen et al. 2006b). Several cell lines were generated, which express VP16-AR, from which three lines (V94, V134, and V149) were selected for study in this work. C14 is a control LNCaP cell line stably transfected with an empty pCINeo vector (Chen et al. 2006b). For the experiments described here, these LNCaP stable cell lines were grown in RPMI 1640 complete medium (Sigma) containing 1-5\% fetal bovine serum (FBS; Hyclone Logan, UT, USA), depending on the experiment, and $0 \cdot 1 \mathrm{mg} / \mathrm{ml}$ neomycin.

\section{Cellular proliferation assay}

C14 or V94 cells were seeded at $3 \times 10^{4}$ cells per well in 24-well plates, with $1 \mathrm{ml}$ RPMI 1640 phenol-free medium containing either 1 or $5 \%$ dextran coated charcoal (DCC)-FBS (Hyclone). After 2-day incubation, the cells were treated with ethanol (vehicle control) or $1 \mathrm{nM}$ R1881. After 0-, 3-, and 6-day incubation periods, the MTT assay was used according to the manufacturer's instructions (Sigma) to determine cell number. In the case of Casodex treatment, $10 \mu \mathrm{M}$ Casodex were added together with ethanol or R1881. Note that the cells with siRNA transfection were treated with R1881, $24 \mathrm{~h}$ after transfection, as described previously (Cai et al. $2007 a)$. Fifty nanomolar of control or sGC $\alpha 1$ siRNA were used (Cai et al. 2007a).

\section{Semi-quantitative RT-PCR and real-time quantitative PCR analyses}

The TRIzol reagent (Invitrogen) was used to isolate total RNA from C14, V94, V134, and V149 cells and subjected to either semi-quantitative reverse transcription 
PCR (RT-PCR) or real-time quantitative PCR (Q-RT-PCR) analysis using SYBR Green (iScript; BioRad). The PCRs were carried out utilizing the following upstream and downstream primers respectively, for each gene: PSA, 5'-GCAGCATTGAACCAGAGGAG-3 ${ }^{\prime}$ and $5^{\prime}$-CCCATGACGTGATACCTTGA-3'; sGC $\alpha 1,5^{\prime}$-AGC AGTGTGGAGAGCTGGAT- $3^{\prime}$ and 5'-CTCATCCAGA GTGCAGTCCA-3'; TMPRSS2, 5'-CACTGTGCATCACC TTGACC-3' ${ }^{\prime}$ and $5^{\prime}$-ACACACCGATTCTCGTCCTC-3'; and GAPDH, $5^{\prime}$-CGACCACTTTGTCAAGCTCA- $3^{\prime}$ and $5^{\prime}$-AGGGGAGATTCAGTGTGGTG-3 ${ }^{\prime}$. Note that GAPDH was used as a control for RNA amount.

\section{Western blotting}

Cell extracts were prepared by boiling cells for $5-10 \mathrm{~min}$ in SDS sample buffer (Chen et al. 2006b). Nitrocellulose blots were probed with antibodies against sGC $\alpha 1$ (Cayman Chemical, Ann Arbor, MI, USA), AR (Upstate, Billerica, MA, USA), VP16 (Clonetech), cyclin-dependent kinase 1 (CDK1) (Cell Signaling, Boston, MA, USA), CDK2 (Santa Cruz Biotechnology, Santa Cruz, CA, USA), CDK4 (Santa Cruz Biotechnology), cyclin D (Santa Cruz Biotechnology), retinoblastoma ( $\mathrm{Rb})$ (Cell Signaling), PSA (Biodesign, Carmel, NY, USA), p27 (Santa Cruz Biotechnology), sGC $\alpha 1$ (Cayman Chemical), $\beta$-actin (Abcam, Cambridge, MA, USA), and $\beta$-tubulin (Chemicon, Billerica, MA, USA), and then developed using the chemiluminescence detection system from Amersham. The cells were treated with $1 \mathrm{nM}$ R1881, with or without $10 \mu \mathrm{M}$ Casodex or $10 \mu \mathrm{g} / \mathrm{ml}$ cycloheximide (CHX). Note that $\beta$-actin or $\beta$-tubulin was used as a control for protein amount.

\section{Immunocytochemistry}

LNCaP cells were grown in 2\% DCC-FBS on glass coverslips and treated with either ethanol (carrier) or $1 \mathrm{nM} \mathrm{R} 1881$ for 2 days. The cells were then fixed with formaldehyde and incubated with Image-iT FX signal enhancer (Molecular Probes, Carlsbad, CA, USA). After rinsing with PBS, the cells were incubated with an antiAR antibody (Santa Cruz Biotechnology). This was followed by staining with secondary antibody (Molecular Probes) and development with ProLong Gold antifade reagent (Molecular Probes). Images were viewed using a confocal microscope (Olympus Fluoview IX70, Center Valley, PA, USA).

\section{Results}

\section{Expression of VP16-AR results in markedly higher AR transcriptional activity}

Since studies have demonstrated that hormone-independent prostate cancer cells exhibit increased AR expression and transcriptional activity (Kokontis et al. 2005) and AR function has been linked to the development and progression of androgen-independent prostate cancer form (Chen et al. 2004), we hypothesized that expression of a hyperactive AR can convert the growth of prostate cancer cells from androgen dependent to androgen independent. In order to test this hypothesis, a hyperactive AR was generated through the fusion of the activation domain of VP16, a strong transcriptional activator (Tiley et al. 1992), with a fulllength AR protein to produce the fusion protein VP16-AR (Fig. 1A). In transient transfection experiments, this fusion protein exhibited strong androgen-dependent transcriptional activity on different promoters, three- to sixfold stronger than endogenous AR in LNCaP cells (Fig. 1B). As shown in Fig. 1C, VP16-AR protein is expressed in this experiment, but this expression is significantly weaker than that of endogenous AR. In addition, and interestingly, androgen has no effect on the stability of this transiently expressed VP16-AR protein, while it is significant on the endogenous AR (Fig. 1C). To better compare the relative activities of VP16-AR and AR, we transfected COS cells that do not express endogenous receptor. This experiment showed that VP16-AR has a fourfold higher activity than AR on PSA-Luc (Shenk et al. 2001) and nearly 20-fold higher on ARE4-Luc (Chen et al. 2006a) (Fig. 1D). The expression levels of the two proteins are comparable (Fig. 1E), arguing that increased activity of VP16-AR is not due to increased protein expression.

To study the biological effects of this hyperactive AR, stable LNCaP cell lines were generated expressing VP16-AR. All VP16-AR-expressing cell lines have elevated R1881-induced AR activity, ranging from 3- to 35-fold better than the endogenous activity found in control C14 cells (Fig. 1F). Interestingly, and surprisingly, V272 cells that exhibited the highest AR activity grew very poorly (Chen \& Shemshedini unpublished results), suggesting that high AR activity that is supraphysiological can be detrimental to the growth of prostate cancer cells. Therefore, we elected to use for the studies the below cell lines with moderately elevated, and thus more physiological, AR activity.

\section{Expression of VP16-AR leads to androgen-indepen- dent growth of prostate cancer cells}

The stable LNCaP cell lines were first monitored for the expression of VP16-AR. RT-PCR was used to show that VP16 was expressed in VP16-AR cells (V94, V134, and V149) but not in control cells (C14) (Fig. 2A). As expected, the three VP16-AR stable cell lines exhibited a markedly higher AR mRNA expression than C14 cells in either the presence or absence of R1881 (Fig. 2A). Western blotting demonstrated expression of VP16-AR protein in all three $\mathrm{V}$ cell lines but not in C14 cells 
A

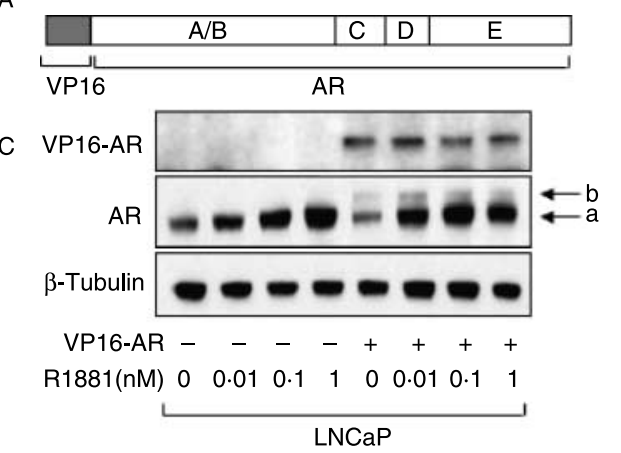

B

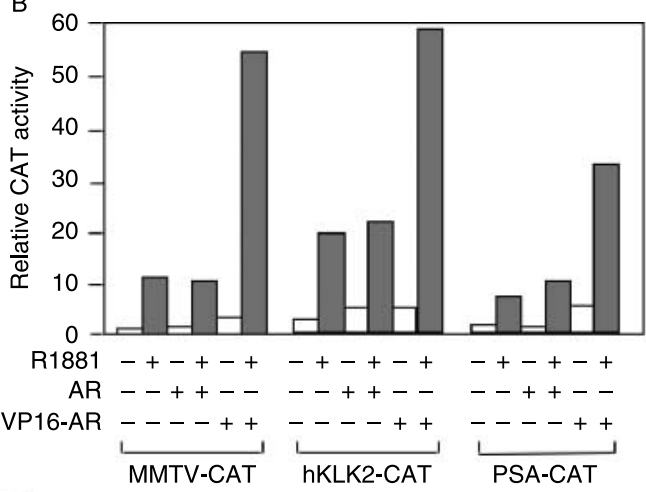

$\mathrm{F}$

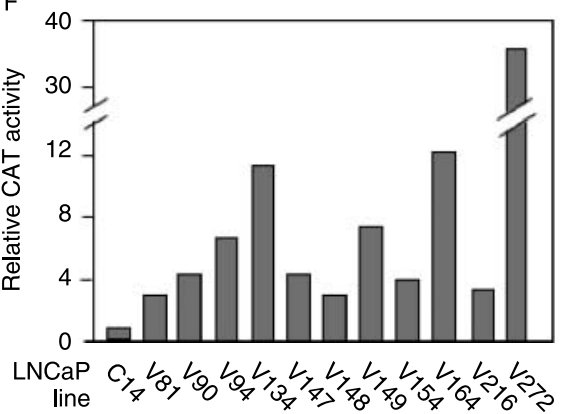

Figure 1 VP16-AR has strong androgen-dependent transcriptional activity in prostate cancer cells. (A) Schematic of the fusion protein VP16-AR that contains the VP16 transactivation domain (amino acids 414-490) fused to the N-terminus of full-length AR. (B) LNCaP cells were transfected with $1 \mu \mathrm{g}$ MMTV-CAT, $5 \mu \mathrm{g}$ hKLK2-CAT, or $5 \mu \mathrm{g}$ PSA-CAT with or without $1 \mu \mathrm{g}$ AR or VP16-AR. One nanomolar of R1881 was used, as indicated. (C) LNCaP cells were transiently transfected with empty vector or VP16-AR and treated with different concentration of R1881, as indicated, for 2 days, and subjected to western blotting using an anti-AR or anti-VP16 antibody. The two right arrows on the AR western blot point to (a) AR and (b) VP16-AR proteins. (D) COS cells were transfected with $1 \mu \mathrm{g}$ PSA-Luc or ARE4-Luc with or without $1 \mu \mathrm{g}$ AR or VP16-AR. One nanomolar of R1881 was used, as indicated. Asterisks indicate statistical significance $(P<0 \cdot 05)$ , as indicated. (E) Western blotting shows similar expression of AR and VP16-AR proteins in transfected COS cells. (F) LNCaP stable cell lines expressing VP16-AR were selected on neomycin-containing medium and screened for androgen-dependent transactivation by transiently transfecting $1 \mu \mathrm{g}$ MMTV-CAT and treated with R1881. Note that C14 cell line represents a stable transfection with an empty $\mathrm{pCl}-\mathrm{Neo}$ vector and V lines represent VP16-AR-expressing cells, with those V lines in boldface selected for further study in this report. All CAT activities are relative to the activity of C14 cells, and this activity was set to 1 . One nanomolar of R1881 was used in B, D, and F.

(Fig. 2B). Additionally, R1881 increased the levels of VP16-AR and the anti-androgen Casodex (bicalutamide) inhibited this positive androgen effect (Fig. 2B), as previously observed with endogenous AR (Bai et al. 2005). This result shows that androgen affects stably expressed VP16-AR but not transiently expressed VP16-AR (Fig. 1C). Further analysis using different concentrations of R1881 revealed that the VP16-AR protein was equally sensitive to the androgen stabilizing effect as native AR (Fig. 2C). To directly measure the stability of these two proteins, the protein synthesis inhibitor CHX was used. CHX had a similar effect on AR and VP16-AR protein levels, and the kinetics of recovery of protein levels induced by R1881 was also similar for AR and VP16-AR (Fig. 2D), indicating that these two proteins do not differ significantly in stability. To examine the expression of these two proteins in cells, immunocytochemistry was performed using an AR antibody that can detect both endogenous AR and VP16-AR. As shown in
Fig. 2E, C14 cells express small levels of AR scattered throughout the cell without androgen. Treatment with R1881 caused increased AR levels and nuclear localization (Fig. 2E), as observed previously (Mora et al. 1996). Interestingly, the $\mathrm{V}$ cell lines express higher protein levels than the $\mathrm{C} 14$ cells, representing signal from AR and VP16-AR, and positive signal is found in the cytoplasm and nucleus (Fig. 2E). Addition of R1881 enhanced these protein levels and induced nuclear localization, just as in C14 cells. Collectively, these data suggest that in the absence of R1881 the V cells have some nuclear VP16-AR protein, which may be responsible for the androgen-independent growth of these cells (Fig. 3).

To test the hypothesis that expression of a hyperactive AR can convert the growth of prostate cancer cells from androgen dependent to androgen independent, the VP16-AR-expressing cells were monitored for cell growth. We performed an MTT growth assay to measure the proliferation of C14, V94, and V149 cells grown in 

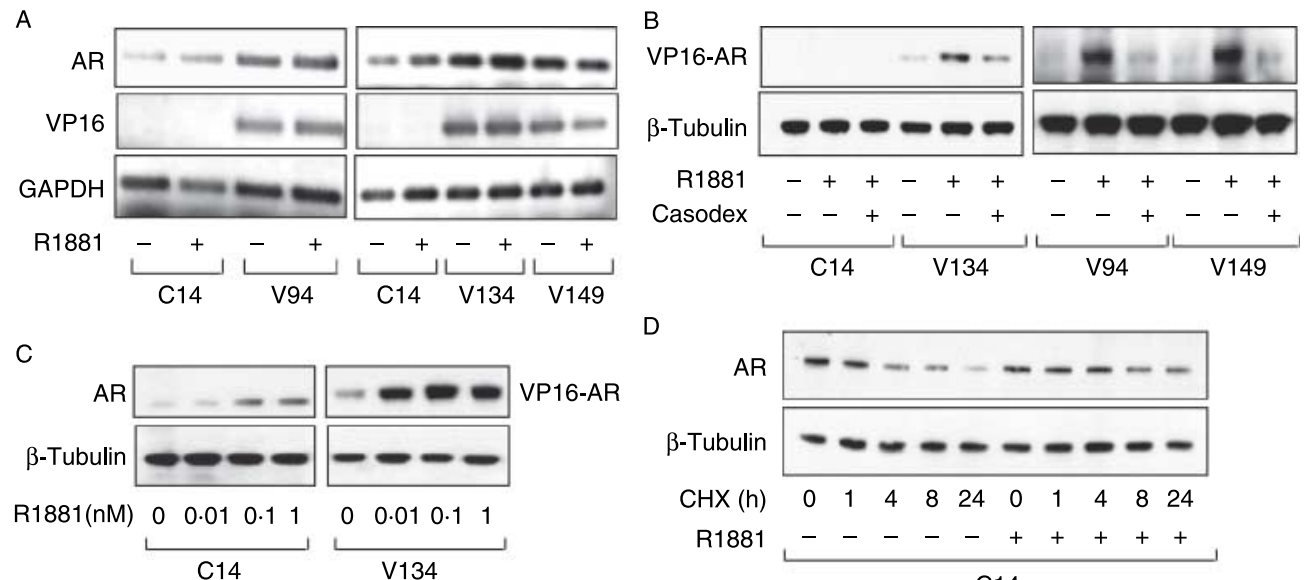

D
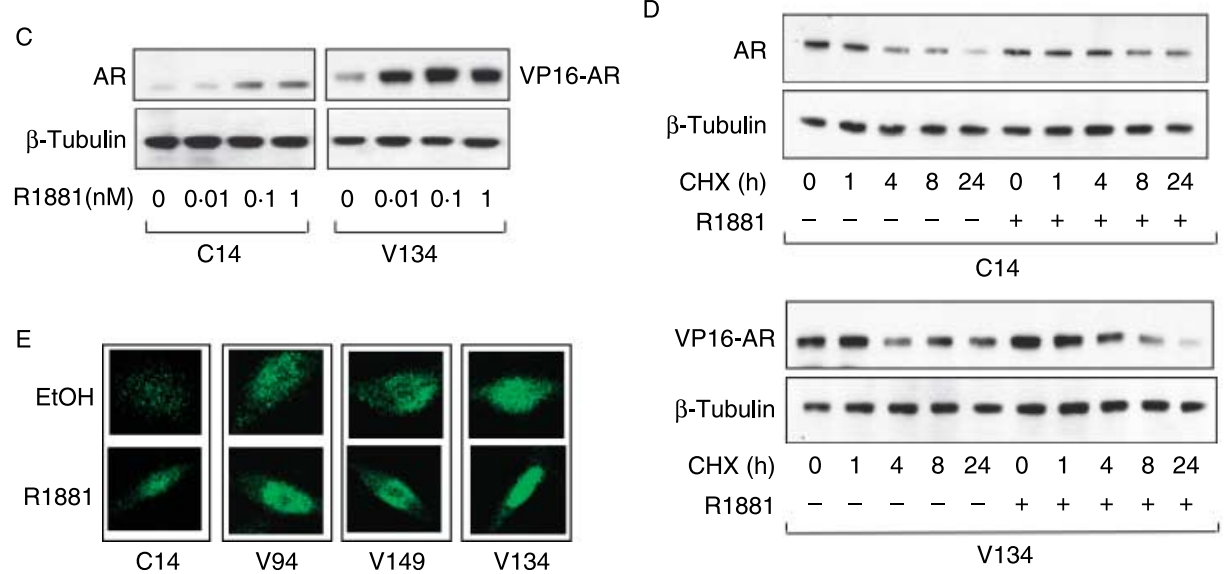

Figure 2 The VP16-AR protein in LNCaP stable cell lines exhibits similar stability to endogenous AR. (A) Semi-quantitative RT-PCR was used to measure the expression of AR or VP16 in C14, V94, V134, and V149 cells in the presence or absence of $1 \mathrm{nM}$ R1881, as indicated. (B-D) Western blotting was used to show that (B) Casodex can reduce VP16-AR protein levels in all three cell lines. (C) R1881 has a similar stabilizing effect on the AR and VP16-AR proteins. (D) Cycloheximide (CHX) effect indicates a similar stability for the AR and VP16-AR proteins. (E) Immunocytochemistry was used to show that VP16-AR-expressing cell lines express higher total AR protein levels than control C14 cells.

steroid-reduced culture medium $(5 \%$ DCC-extracted serum). Under these growth conditions, C14 cells did not grow in the absence of R1881 (Fig. 3A and B). However, and importantly, both V94 (Fig. 3A) and V149 (Fig. 3B) cells exhibited a time-dependent increase in cell number in the absence of androgens, and this growth is statistically higher than that of C14 cells. In fact, the androgen-independent growth of V149 cells is comparable with the androgen-induced growth of C14 cells (Fig. 3B). Collectively, these data show that expression of VP16-AR in LNCaP cells leads to androgen-independent cell growth. Interestingly, despite the androgen-independent growth of V94 and V149 cells, this growth is enhanced by R1881 treatment, and V94 cells grew statistically better than C14 cells in the presence of R1881 (Fig. 3A and B).

To demonstrate that the growth of V94 and V149 cells in the absence of exogenous androgen was indeed androgen independent, cell growth was measured in the presence of Casodex. As shown in Fig. 3C, Casodex suppressed the R1881-induced growth of C14, V94, and V149 cells, but had no effect on the R1881-independent growth of V94 and V149 cells. Interestingly, Casodex almost completely inhibited the growth of C14 cells, while it only reduced the growth of V94 and V149 cells to the level observed in the absence of R1881 (Fig. 3C).
These data show that the VP16-AR-expressing cells exhibit a growth phase that is insensitive to Casodex and thus independent of androgens.

Our data above (Fig. 3A-C) demonstrate that V94 and V149 cells grow better in the presence of R1881 than in its absence, suggesting that their growth is androgen inducible. To get a relative measure of the androgen sensitivity of these cells, their growth was compared with that of $\mathrm{C} 14$ cells under very low serum (1\% DCC-extracted serum) conditions and different concentrations of R1881. As shown in Fig. 3B, the growth profiles of V94 and V149 cells were similar to C14 cells. All three cell lines exhibited a growth response at an R1881 concentration of $0 \cdot 01-0 \cdot 1 \mathrm{nM}$ and optimal growth at $1 \mathrm{nM}$ (Fig. 3D). Interestingly, the V149 cells elicited the highest growth response to R1881 treatment and C14 cells the lowest (Fig. 3D). Collectively, these data show that V94 and V149 cells exhibit androgen-independent proliferation that is androgen inducible.

\section{VP16-AR-expressing cells display altered expression of cell cycle regulatory proteins}

To begin to understand the molecular mechanism responsible for the androgen-independent growth of 

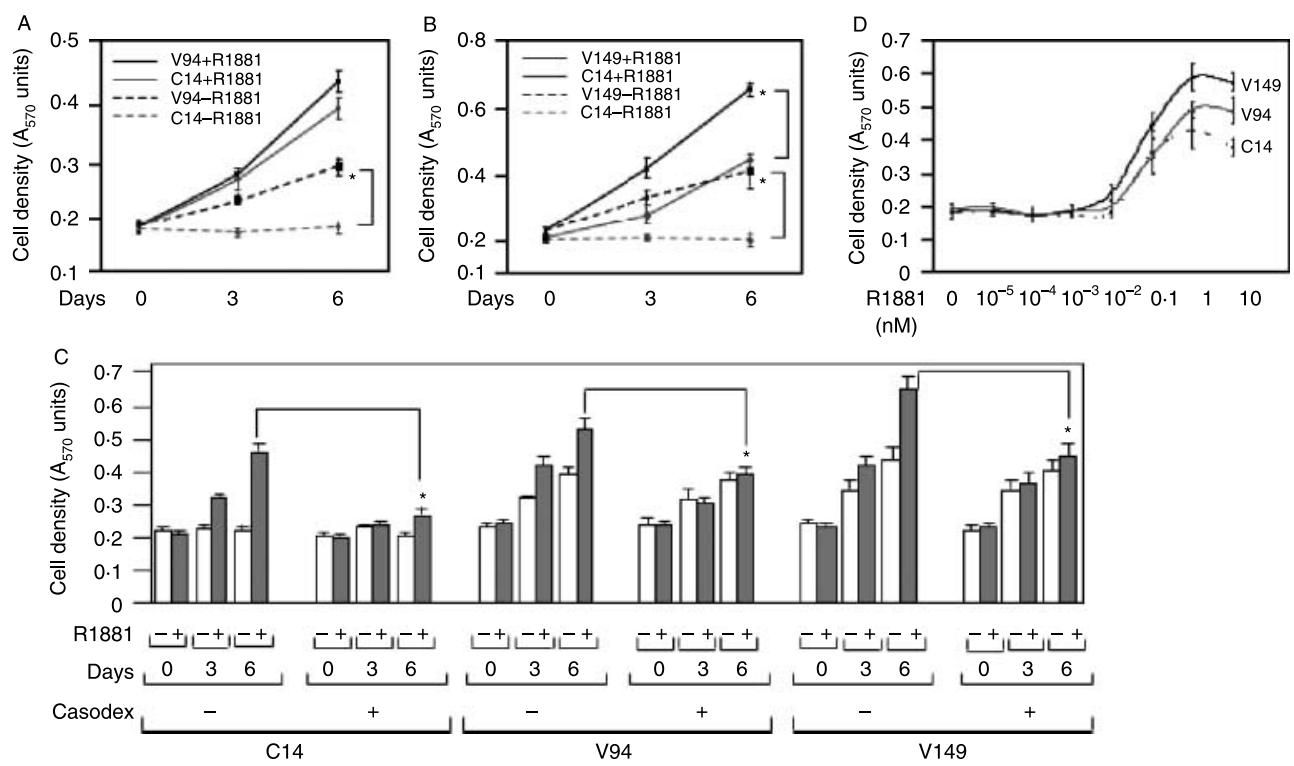

Figure 3 Expression of VP16-AR leads to androgen-independent growth of prostate cancer cells. (A) V94 or (B) V149 cells were measured for proliferation in the presence (solid black line) or absence (dashed black line) of $1 \mathrm{nM}$ R1881 for 0-6 days in medium containing 5\% DCC-extracted serum, and compared with the proliferation of C14 cells (solid gray line, with R1881; dashed gray line, without R1881). (C) C14, V94, or V149 cells were measured for proliferation under the same conditions as above, with or without Casodex. Bar graphs represent the average of three independent experiments plus the s.D. (D) The same three cell lines were grown for 6 days in a medium containing $1 \%$ DCC-extracted serum, with increasing concentrations of R1881, as indicated. Each point in A, B, and D represents the average of three independent experiments plus/minus the S.D. Asterisks indicate statistical significance $(P<0.05)$ on the effect of Casodex on cell growth.

VP16-AR-expressing cells, we used western blotting to measure the expression of several cell cycle regulatory proteins (Fig. 4). Rb protein expression was repressed by androgen in C14 cells, as shown previously (Taneja et al. 2002). Interestingly, $\mathrm{Rb}$ expression was significantly reduced in V94 cells, but only in the absence of androgen, when compared with C14 cells. In contrast to C14 cells, however, R1881 induced Rb expression in V94 cells. V94 cells expressed reduced levels of p27 when compared with C14 control cells, in both the presence and absence of R1881. As shown in Fig. 4, CDK1 and CDK2 are expressed each as one protein band in C14 cells, while in V94 cells there is a second, more slowly migrating, band that appears for both proteins. On the other hand, CDK4 expression is the same in C14 and V94 cells.

\section{Expression of $S G C \alpha 1$ is androgen independent in VP16-AR-expressing prostate cancer cells}

To understand the molecular basis of the androgenindependent growth of the VP16-AR cells, the expression of several androgen-regulated genes was measured. Since our previous data indicate that sGC $\alpha 1$ is important in the growth of both androgen-dependent and androgen-independent LNCaP cells (Cai et al. $2007 a$ ), we first measured sGC $\alpha 1$ expression in our
VP16-AR-expressing cells. Interestingly, the expression of sGC $\alpha 1$, as measured by semi-quantitative RT-PCR (Fig. 5A and B), QRT-PCR (Fig. 5C), and western blotting (Fig. 5D), is androgen independent in V94, V134, and V149 cells, mimicking what has been observed in the other androgen-independent prostate cancer cells (Cai et al. 2007a; Cai \& Shemshedini unpublished results). This androgen-independent expression is not a common feature of all androgenregulated genes, since TMPRSS2 (Lin et al. 1999) is androgen induced in both the C14 and VP16-AR cell lines (Fig. 5A-C). We have also confirmed androgen regulation in V94 cells of the PSA and hKLK2 genes (Fig. 5A; Cai \& Shemshedini unpublished observations). These findings, together with our data from other androgen-independent prostate cancer cells (Cai et al. 2007a; Cai \& Shemshedini unpublished observations), strongly argue that androgen-unresponsive expression of sGC $\alpha 1$ may be a common property of hormone-refractory prostate cancer cells.

Previous studies have shown that Casodex can induce expression of PSA in prostate cancer cells that overexpress AR (Chen et al. 2004). To determine whether this is also true for our VP16-AR-expressing cells, PSA expression was measured by semi-quantitative RT-PCR in cells treated with Casodex. As shown in Fig. 5E, Casodex had a weak negative effect on PSA expression in V94 and V149 cells, the same as C14 control cells. 


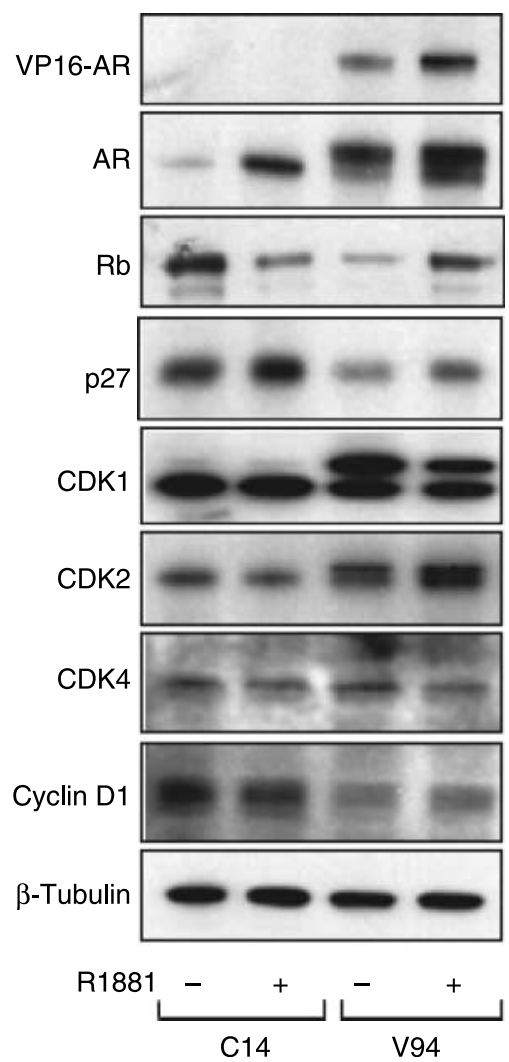

Figure 4 VP16-AR-expressing prostate cancer cells exhibit differential expression of cell cycle proteins. C14 and V94 cells were grown for 2 days in the presence or absence of $1 \mathrm{nM}$ R1881, as indicated, and subjected to western blotting to measure the expression of VP16-AR, AR, Rb, p27, CDK1, CDK2, CDK4, cyclin $D 1$, and $\beta$-tubulin. Note that the V94 cells express two proteins detected by the anti-AR antibody, endogenous AR, and VP16-AR (upper band).

Interestingly, however, the basal expression of PSA is higher in the VP16-AR cells than in the control cells. By contrast, R1881 was able to induce PSA expression in all three cell lines (Fig. 5E). Similar results were obtained for PSA protein expression with R1881 and Casodex, although the protein levels varied in different cell lines (Fig. 5F). These results demonstrate that Casodex does not have agonistic activity in VP16-AR-expressing cells.

\section{sGC $\alpha 1$ is involved in the androgen-independent growth of VP16-AR-expressing prostate cancer cells}

To directly test whether sGC $\alpha 1$ is involved in V94 cell proliferation, a growth assay was performed, in which sGC $\alpha 1$ expression was diminished by siRNA transfection. Transfection of sGCal siRNA markedly downregulates the endogenous expression of sGC $\alpha 1 \mathrm{mRNA}$ in V94 cells, when compared with control siRNA (Fig. 6A), as has been observed in C14 cells (Cai et al. $2007 a$ ). The same effect was observed on sGC $\alpha 1$ protein levels in V94 and C14 cells (Fig. 6B). This reduction in sGC $\alpha 1$ expression results in significantly decreased growth of C14 cells (Fig. 6C), as shown previously (Cai et al. 2007a). Most significantly, sGC $\alpha 1$ siRNA also inhibited the growth of V94 cells both in the presence and absence of androgens (Fig. 6D). These findings strongly suggest that sGC $\alpha 1$ is required for the androgen-independent growth of V94 cells.

\section{Discussion}

Transcriptionally active AR is present in all forms of prostate cancer (Trapman \& Cleutjens 1997, Meehan \& Sadar 2003). Among the multiple mechanisms implicated in the conversion of prostate cancer growth from androgen sensitive to androgen insensitive (reviewed in Jenster 1999), overexpression of AR has been recently shown to be sufficient for this transition (Chen et al. 2004). In support of this, several earlier studies have demonstrated that hormone-independent prostate cancer cell lines exhibit increased AR expression and transcriptional activity (Kokontis et al. 1998, Culig et al. 1999, Gao et al. 1999, Lu et al. 1999, Thalmann et al. 2000). In addition, clinical studies have shown that about $30 \%$ of advanced prostate tumors exhibit AR overexpression (Visakorpi et al. 1995, Koivisto et al. 1997, Palmberg et al. 1997). These studies collectively led us to hypothesize that increased AR transcriptional activity, like increased AR expression, can promote androgen-independent growth of prostate cancer cells. This hypothesis was directly tested by expression in LNCaP cells of VP16-AR, a fusion protein that harbors androgen-inducible transcriptional activity that is tenfold higher than the endogenous AR. We demonstrate in this study that cells expressing VP16-AR do indeed exhibit androgen-independent growth under the same culture conditions that yield only androgendependent growth for parental LNCaP cells (Fig. 3). Interestingly, however, the growth of VP16-AR cells is higher in the presence of R1881 demonstrating that, while these cells can proliferate in an androgenindependent manner, the presence of this androgen can further accelerate their growth. Thus, our VP16-AR cells are both androgen independent and androgen inducible, suggesting that the VP16-AR fusion protein has two growth-promoting functions, one that depends on androgens and another that does not. This conclusion is supported by our experiments with Casodex, since this anti-androgen only partially inhibited the growth of VP16-AR cells. Indeed, Casodex reduces the growth of VP16-AR cells to a level that is observed in the absence of androgens, implying strongly that there is an androgen-independent and an androgen-dependent component to the growth of VP16-AR cells. 
A

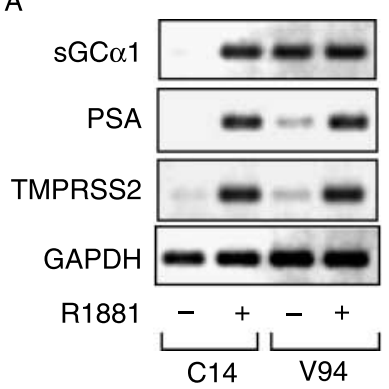

B

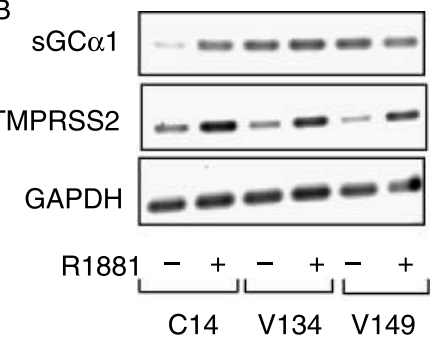

D

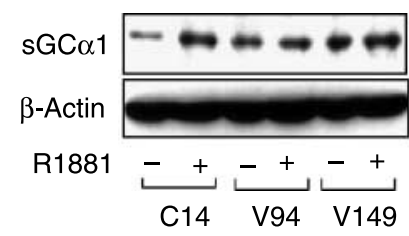

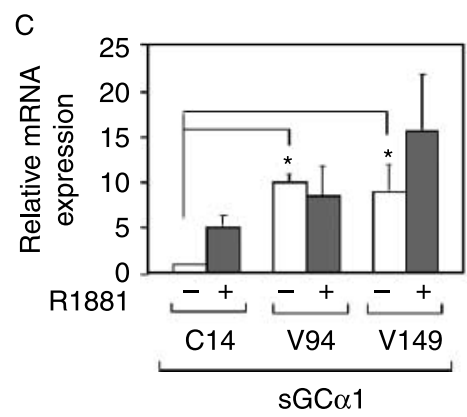

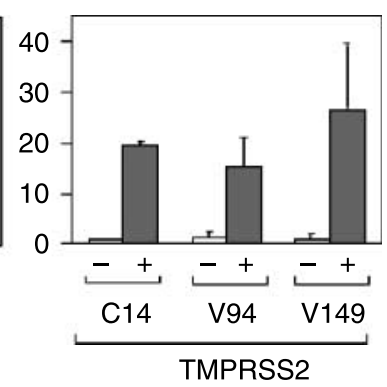

E
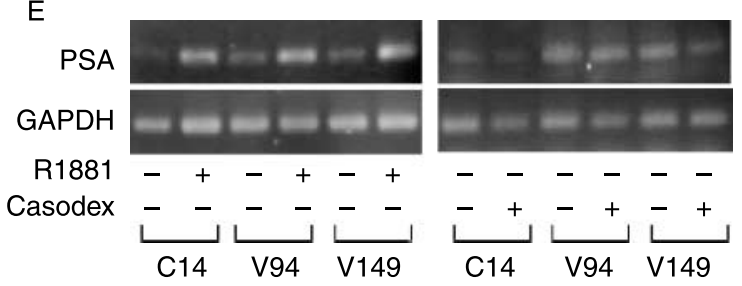

$\mathrm{F}$

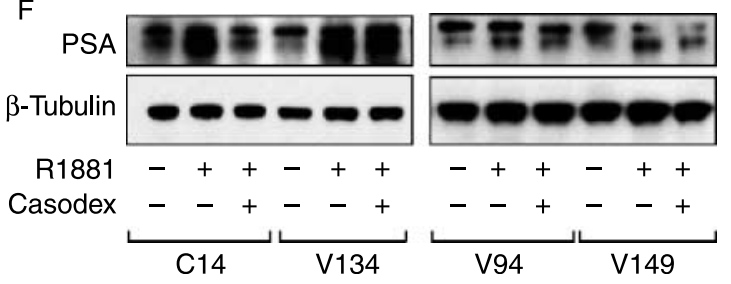

Figure 5 The expression of SGC $\alpha 1$ is constitutive in VP16-AR-expressing prostate cancer cells. The expression of sGC $\alpha 1$, PSA, and/or

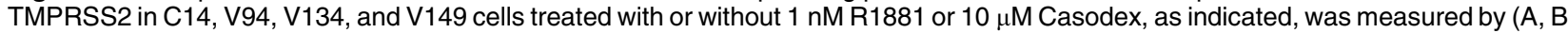
and E) semi-quantitative RT-PCR, (C) Q-RT-PCR, or (D and F) western blotting. Note that mRNA levels measured by Q-RT-PCR are represented relative to GAPDH expression $(C)$. Note that the PSA protein in $(F)$ is the lower band. Asterisks indicate statistical significance $(P<0.05)$ on the sGC $\alpha 1$ expression in V94 and V149 cells when compared with $\mathrm{C} 14$ cells. Note that there is no statistically significant DHT effect on SGC $\alpha 1$ expression in either V94 or V149 cells (C).

In view of the recent study reporting that increased AR expression is sufficient to convert prostate cancer cell growth from hormone sensitive to hormone refractory (Chen et al. 2004), it is possible that our VP16-AR cells simply represent another example of androgen-independent growth in response to AR overexpression. However, the data provided argue against this and suggest that our cells may represent another cellular state of hormone-refractory prostate cancer. First, and most importantly, we have no evidence that the antagonist Casodex has any agonistic activity in VP16-AR cells, as observed in AR overexpressing cells (Chen et al. 2004). Indeed, the VP16-AR cells exhibited no detectable Casodexinduced expression of PSA (Fig. 5E and F) or of several other androgen-regulated genes (Hsieh \& Shemshedini unpublished observations). Secondly, AR overexpression in LNCaP cells increased their sensitivity to R1881-induced growth (Chen $e$ t al. 2004), while expression of VP16-AR had no effect (Fig. 3D).
Thus, our VP16-AR cells are likely to represent a mechanism of androgen independence, which depends more on elevated AR transcriptional activity than expression level. Since no more than $30 \%$ of advanced prostate tumors exhibit increased AR expression (Visakorpi et al. 1995, Koivisto et al. 1997, Palmberg et al. 1997), it is possible that our VP16-AR cells may mimic one cancer cellular state that is found among the remaining $70 \%$ of tumors lacking increased AR expression. The question remains of what other mechanisms in addition to AR gene amplification can lead to AR overexpression. One can speculate that mutations in the AR gene promoter disrupting the activities of silencer elements can lead to higher AR expression. It is also possible that mutations that disrupt the activity of transcriptional repressors that act on the AR promoter can have the same effect. Perhaps these mechanisms are operating in some prostate tumors, but empirical evidence needs to be obtained in the future. 
A

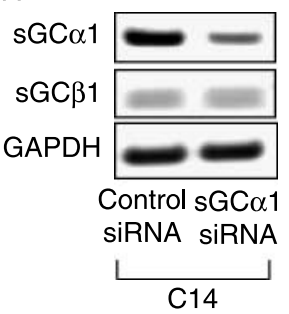

C

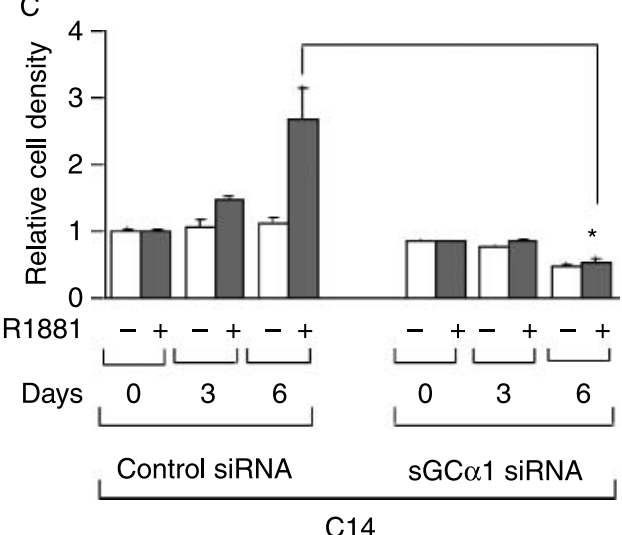

B

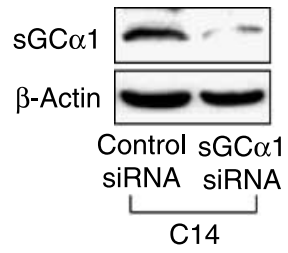

$\mathrm{sGC} \alpha 1$

$\beta$-Actin

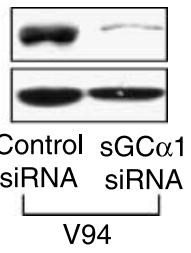

D

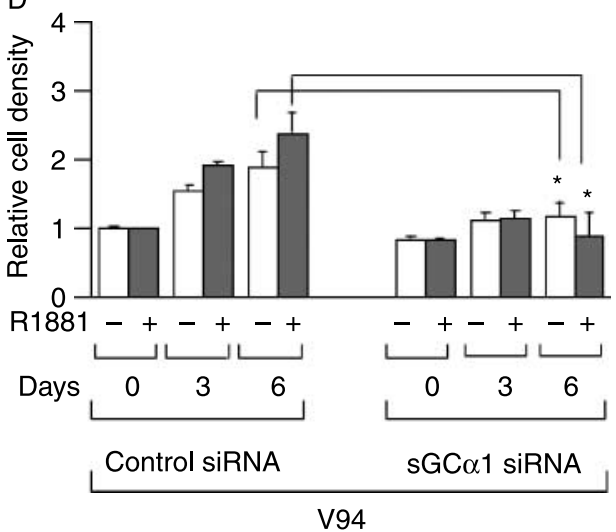

Figure 6 sGC $\alpha 1$ is involved in the androgen-independent growth of V94 cells. (A) V94 cells were transfected with sGC $\alpha 1$ siRNA or an unrelated control siRNA, and expression of sGC $\alpha 1$ and sGC $\beta 1$ was measured by semi-quantitative RT-PCR. (B) Western blotting shows reduced sGC $\alpha 1$ protein expression in $\mathrm{C} 14$ or V94 cells transfected with sGC $\alpha 1$ siRNA. (C) C14 or (D) V94 cells were transfected with sGC $\alpha 1$ siRNA or control siRNA and grown for 0-6 days in the presence or absence of $1 \mathrm{nM}$ R1881, as indicated, and measured for cell number. Bar graphs represent the average of three independent experiments plus the S.D. Asterisks indicate statistical significance $(P<0.05)$ on the effect of sGC $\alpha 1$ siRNA on cell growth.

The molecular changes responsible for the hormonerefractory cancer state in tumors expressing normal AR protein levels are poorly understood. Several mechanisms have been suggested (reviewed in Jenster 1999), including AR mutations that broaden ligand specificity, generation of signaling pathways that lead to ligand-independent activation of AR, and overexpression of AR coactivators. All these provide means by which to activate AR, but they do not address the issue of AR-regulated gene expression that may be responsible for the hormone-refractory cancer state. Our VP16-AR cells provide some insight into this, with our discovery that these cells express the sGC $\alpha 1$ gene, an AR-regulated gene (Cai et al. 2007a), in a hormoneindependent manner (Fig. 5A-C). sGC $\alpha 1$ is a component of sGC, the enzyme that catalyzes cGMP synthesis in response to nitric oxide (reviewed in Hanafy et al. 2001). Our earlier study showed that sGC $\alpha 1$ expression is androgen independent in C81 cells (Cai et al. 2007a), a hormone-refractory LNCaP cell line whose AR expression is similar to that of the androgendependent parental cells (Igawa et al. 2002). Furthermore, we demonstrated that $\mathrm{sGC} \alpha 1$ protein expression levels are directly related to the growth capacity of LNCaP cells (Cai et al. 2007a). While the molecular mechanism responsible for the sGC $\alpha 1$ role in cell proliferation is not yet known, it is clear from our data thus far that the sGC $\alpha 1$ protein levels are directly proportional to the growth capacity of prostate cancer cells (Cai et al. 2007a). As expected, we find in this study that endogenous sGC $\alpha 1$ expression is also required for the androgen-independent growth of VP16-AR cells (Fig. 6D), suggesting that androgen-independent expression of sGC $\alpha 1$ may be responsible for the hormone-refractory growth of LNCaP cells. Importantly, the transition to androgen-independent expression of sGCal is not unique to LNCaP cells, but may be a common property of prostate cancer cells since we have observed a similar expression pattern in hormone-refractory CWR22-Rv1 (Wainstein et al. 1994) and Mda-P109 (Navone et al. 1997) cells (Cai \& Shemshedini unpublished observations).

It is interesting to note that androgen-independent expression is not observed globally on AR-regulated genes in hormone-refractory cells, but in fact is target gene specific. Our VP16-AR cells here (Fig. 5A and B) and C81 cells (Igawa et al. 2002) exhibit androgeninduced expression of two hallmark AR-regulated genes, PSA and TMPRSS2. The contrasting expression patterns of PSA and TMPRSS2 when compared with 
sGC $\alpha 1$ suggest that genes important in prostate cancer biology are selected for hormone-independent expression. This is supported by another novel AR-regulated gene, ETV1, and also elicits androgenindependent expression in VP16-AR (Cai \& Shemshedini unpublished observations) and C81 cells (Cai et al. 2007b). ETV1 is involved in prostate cancer cell invasiveness (Cai et al. 2007b) and sGCa1 in cell proliferation (Cai et al. 2007a), both processes essential to the progression of prostate cancer. For now, we do not know how many more AR-regulated genes transition to androgen-independent expression or the molecular basis of the gene selection process for such expression. These will be the two important objectives of future work.

Previous work has suggested that reduced $\mathrm{Rb}$ protein expression may be responsible for androgen-induced proliferation of LNCaP cells (Taneja et al. 2002). In support of this, we observed that $\mathrm{R} 1881$ repressed $\mathrm{Rb}$ expression in LNCaP cells (C14 cells; Fig. 4). Interestingly, $\mathrm{Rb}$ expression is even lower in the V94 cells without androgen than C14 cells with androgen (Fig. 4), suggesting that reduced levels of $\mathrm{Rb}$ in $\mathrm{V}$ cells may be involved in their androgen-independent growth. Surprisingly, however, Rb levels are higher in V94 cells treated with androgen than without, indicating a complex function of $\mathrm{Rb}$ in prostate cancer cell growth. On the other hand, protein levels of p27 (Kip1) are consistently and significantly lower in V94 than C14 cells (Fig. 4). In view of previous findings showing that increased levels of p27 are associated with decreased prostate cancer cell growth and increased cell cycle arrest (Deep et al. 2007), our finding suggests that decreased p27 expression in V cells may be in part responsible for the increased growth capacity of these cells. Supporting this conclusion is the previous finding that decreased expression of p27 is associated with androgen-independent proliferation of LNCaP cells (Murillo et al. 2001). Previous data also suggest that increased levels of CDKs and cyclins are found in proliferating LNCaP cells (Deep et al. 2007). While we observed no significant change in CDK expression between C14 and V94 cells, a second larger band was detected for both CDK1 and CDK2 in V94 cells (Fig. 4). These larger proteins may represent phosphorylated forms of CDK1 and CDK2, which may be involved in androgen-independent growth of our LNCaP cell lines. Collectively, these data, together with the surprising finding that cyclin D1 expression is reduced in V94 when compared with C14 cells (Fig. 4), show the complex nature of cell cycle regulatory proteins in LNCaP cells. Future work will be directed to a biochemical analysis of the larger CDK proteins and determining what roles these proteins, as well as $\mathrm{Rb}$ and p27, play in cell cycle progression of VP16-AR-expressing cells.

\section{Acknowledgements}

This work was supported by a grant from National Institutes of Health (2R15DK067059). The authors declare that there is no conflict of interest that would prejudice the impartiality of this scientific work.

\section{References}

Bai VU, Cifuentes E, Menon M, Barrack ER \& Reddy GP 2005 Androgen receptor regulates Cdc6 in synchronized LNCaP cells progressing from G1 to S phase. Journal of Cellular Physiology 204 381-387.

Beato M \& Klug J 2000 Steroid hormone receptors: an update. Human Reproduction Update 6 225-236.

Berger SL, Cress WD, Cress A, Triezenberg SJ \& Guarente L 1990 Selective inhibition of activated but not basal transcription by the acidic activation domain of VP16: evidence for transcriptional adaptors. Cell 61 1199-1208.

Brinkmann AO, Jenster G, Ris-Stalpers C, van der Korput JA, Bruggenwirth HT, Boehmer AL \& Trapman J 1995 Androgen receptor mutations. Journal of Steroid Biochemistry and Molecular Biology 53 443-448.

Bubulya A, Wise SC, Shen XQ, Burmeister LA \& Shemshedini L 1996 c-Jun can mediate androgen receptor-induced transactivation. Journal of Biological Chemistry 271 24583-24589.

Bubulya A, Chen SY, Fisher CJ, Zheng Z, Shen XQ \& Shemshedini L 2001 c-Jun potentiates the functional interaction between the amino and carboxyl termini of the androgen receptor. Journal of Biological Chemistry 276 44704-44711.

Cai C, Chen SY, Zheng Z, Omwancha J, Lin MF, Balk SP \& Shemshedini L 2007a Androgen regulation of soluble guanylyl cyclase alphal mediates prostate cancer cell proliferation. Oncogene 26 1606-1615.

Cai C, Hsieh CL, Omwancha J, Zheng Z, Chen SY, Baert JL \& Shemshedini L $2007 b$ ETV1 is a novel androgen receptor-regulated gene that mediates prostate cancer cell invasion. Molecular Endocrinology 21 1835-1846.

Chang CS, Kokontis J \& Liao ST 1988 Molecular cloning of human and rat complementary DNA encoding androgen receptors. Science $\mathbf{2 4 0}$ 324-326.

Chen CD, Welsbie DS, Tran C, Baek SH, Chen R, Vessella R, Rosenfeld MG \& Sawyers CL 2004 Molecular determinants of resistance to antiandrogen therapy. Nature Medicine 10 33-39.

Chen SY, Wulf G, Zhou XZ, Rubin MA, Lu KP \& Balk SP $2006 a$ Activation of $\beta$-catenin signaling in prostate cancer by peptidylprolyl isomerase Pin1-mediated abrogation of the androgen receptor- $\beta$-catenin interaction. Molecular and Cellular Biology 26 929-939.

Chen SY, Cai C, Fisher CJ, Zheng Z, Omwancha J, Hsieh CL \& Shemshedini L $2006 b$ c-Jun enhancement of androgen receptor transactivation is associated with prostate cancer cell proliferation. Oncogene 25 7212-7223.

Culig Z, Hoffmann J, Erdel M, Eder IE, Hobisch A, Hittmair A, Bartsch G, Utermann G, Schneider MR, Parczyk K et al. 1999 Switch from antagonist to agonist of the androgen receptor bicalutamide is associated with prostate tumour progression in a new model system. British Journal of Cancer $\mathbf{8 1}$ 242-251.

Cussenot O, Berthon P, Cochand-Priollet B, Maitland NJ \& Le Duc A 1994 Immunocytochemical comparison of cultured normal epithelial prostatic cells with prostatic tissue sections. Experimental Cell Research 214 83-92.

Deep G, Oberlies NH, Kroll DJ \& Agarwal R 2007 Isosilybin B and isosilybin A inhibit growth, induce G1 arrest, and cause apoptosis in human prostate cancer LNCaP and 22Rv1 cells. Carcinogenesis $\mathbf{2 8}$ $1533-1542$. 
Eder IE, Culig Z, Ramoner R, Thurnher M, Putz T, Nessler-Menardi C, Tiefenthaler M, Bartsch G \& Klocker H 2000 Inhibition of LncaP prostate cancer cells by means of androgen receptor antisense oligonucleotides. Cancer Gene Therapy 7 997-1007.

Gao M, Ossowski L \& Ferrari AC 1999 Activation of Rb and decline in androgen receptor protein precede retinoic acid-induced apoptosis in androgen-dependent LNCaP cells and their androgen-independent derivative. Journal of Cellular Physiology 179 336-346.

Han G, Buchanan G, Ittmann M, Harris JM, Yu X, Demayo FJ, Tilley W \& Greenberg NM 2005 Mutation of the androgen receptor causes oncogenic transformation of the prostate. PNAS 102 1151-1156.

Hanafy KA, Krumenacker JS \& Murad F 2001 NO, nitrotyrosine, and cyclic GMP in signal transduction. Medical Science Monitor 7 801-819.

Igawa T, Lin FF, Lee MS, Karan D, Batra SK \& Lin MF 2002 Establishment and characterization of androgen-independent human prostate cancer LNCaP cell model. Prostate 50 222-235.

Jenster G 1999 The role of the androgen receptor in the development and progression of prostate cancer. Seminars in Oncology 26 407-421.

Jiang J, Wang LF, Fang YH, Jin FS \& Jin WS 2004 Proliferative response of human prostate cancer cell to hormone inhibited by androgen receptor antisense RNA. Chinese Medical Journal 117 684-688.

Kastner P, Mark M \& Chambon P 1995 Nonsteroid nuclear receptors: what are genetic studies telling us about their role in real life? Cell 83 859-869.

Koivisto P, Kononen J, Palmberg C, Tammela T, Hyytinen E, Isola J, Trapman J, Cleutjens K, Noordzij A, Visakorpi T et al. 1997 Androgen receptor gene amplification: a possible molecular mechanism for androgen deprivation therapy failure in prostate cancer. Cancer Research 57 314-319.

Kokontis JM, Hay N \& Liao S 1998 Progression of LNCaP prostate tumor cells during androgen deprivation: hormone-independent growth, repression of proliferation by androgen, and role for p27Kipl in androgen-induced cell cycle arrest. Molecular Endocrinology 12 941-953.

Kokontis JM, Hsu S, Chuu CP, Dang M, Fukuchi J, Hiipakka RA \& Liao S 2005 Role of androgen receptor in the progression of human prostate tumor cells to androgen independence and insensitivity. Prostate 65 287-298.

Lin B, Ferguson C, White JT, Wang S, Vessella R, True LD, Hood L \& Nelson PS 1999 Prostate-localized and androgen-regulated expression of the membrane-bound serine protease TMPRSS2. Cancer Research 59 4180-4184.

Lu S, Tsai SY \& Tsai MJ 1999 Molecular mechanisms of androgenindependent growth of human prostate cancer LNCaP-AI cells. Endocrinology 140 5054-5059.

Mangelsdorf DJ \& Evans RM 1995 The RXR heterodimers and orphan receptors. Cell 83 841-850.

Mangelsdorf DJ, Thummel C, Beato M, Herrlich P, Schutz G, Umesono K, Blumberg B, Kastner P, Mark M, Chambon P et al. 1995 The nuclear receptor superfamily: the second decade. Cell 83 835-839.

Marcelli M, Ittmann M, Mariani S, Sutherland R, Nigam R, Murthy L, Zhao Y, DiConcini D, Puxeddu E, Esen A et al. 2000 Androgen receptor mutations in prostate cancer. Cancer Research 60 944-949.

Meehan KL \& Sadar MD 2003 Androgens and androgen receptor in prostate and ovarian malignancies. Frontiers in Bioscience $\mathbf{8}$ d780-d800.

Mora GR, Prins GS \& Mahesh VB 1996 Autoregulation of androgen receptor protein and messenger RNA in rat ventral prostate is protein synthesis dependent. Journal of Steroid Biochemistry and Molecular Biology 58 539-549.
Murillo H, Huang H, Schmidt LJ \& Tindall DJ 2001 Role of PI3K signaling in survival and progression of LNCaP prostate cancer cells to the androgen refractory state. Endocrinology 142 $4795-4805$

Navone NM, Olive M, Ozen M, Davis R, Troncoso P, Tu SM, Johnston D, Pollack A, Pathak S, von Eschenbach AC et al. 1997 Establishment of two human prostate cancer cell lines derived from a single bone metastasis. Clinical Cancer Research 3 2493-2500.

Palmberg C, Koivisto P, Hyytinen E, Isola J, Visakorpi T, Kallioniemi OP \& Tammela T 1997 Androgen receptor gene amplification in a recurrent prostate cancer after monotherapy with the nonsteroidal potent antiandrogen Casodex (bicalutamide) with a subsequent favorable response to maximal androgen blockade. European Urology $31216-219$

Roznovanu SL, Amalinci C \& Radulescu D 2005 Molecular mechanisms in hormone-resistant prostate cancer. Revista MedicoChirurgicală a Societăţii de Medici și Naturalissti din Iași 109 577-583.

Russell PJ \& Kingsley EA 2003 Human prostate cancer cell lines. Methods in Molecular Medicine 81 21-39.

Shenk JL, Fisher CJ, Chen SY, Zhou XF, Tillman K \& Shemshedini L 2001 p53 represses androgen-induced transactivation of prostatespecific antigen by disrupting hAR amino- to carboxyl-terminal interaction. Journal of Biological Chemistry 276 38472-38479.

Singh SM, Gauthier S \& Labrie F 2000 Androgen receptor antagonists (antiandrogens): structure-activity relationships. Current Medicinal Chemistry 7 211-247.

Smith PC, Hobisch A, Lin DL, Culig Z \& Keller ET 2001 Interleukin-6 and prostate cancer progression. Cytokine and Growth Factor Reviews 12 33-40.

Taneja SS, Ha S \& Garabedian MJ 2002 Androgen stimulated cellular proliferation in the human prostate cancer cell line LNCaP is associated with reduced Retinoblastoma protein expression. Journal of Cellular Biochemistry 84 188-200.

Thalmann GN, Sikes RA, Wu TT, Degeorges A, Chang SM, Ozen M, Pathak S \& Chung LW 2000 LNCaP progression model of human prostate cancer: androgen-independence and osseous metastasis. Prostate 44 91-103 (Jul 101; 144(102)).

Thummel CS 1995 From embryogenesis to metamorphosis: the regulation and function of Drosophila nuclear receptor superfamily members. Cell 83 871-877.

Tiley LS, Madore SJ, Malim MH \& Cullen BR 1992 The VP16 transcription activation domain is functional when targeted to a promoter-proximal RNA sequence. Genes and Development 6 2077-2087.

Trapman J \& Cleutjens KB 1997 Androgen-regulated gene expression in prostate cancer. Seminars in Cancer Biology 8 29-36.

Visakorpi T, Hyytinen E, Koivisto P, Tanner M, Keinanen R, Palmberg C, Palotie A, Tammela T, Isola J \& Kallioniemi OP 1995 In vivo amplification of the androgen receptor gene and progression of human prostate cancer. Nature Genetics 9 401-406.

Wainstein MA, He F, Robinson D, Kung HJ, Schwartz S, Giaconia JM, Edgehouse NL, Pretlow TP, Bodner DR, Kursh ED et al. 1994 CWR22: androgen-dependent xenograft model derived from a primary human prostatic carcinoma. Cancer Research $\mathbf{5 4} 6049-6052$.

Received in final form 21 March 2008

Accepted 8 May 2008

Made available online as an Accepted Preprint 8 May 2008 